\title{
A consistent failure of the power law for lifted weight ${ }^{1}$
}

\author{
JOHN ROSS AND VINCENT DI LOLLO ${ }^{2}$ \\ THE UNIVERSITY OF WESTERN AUSTRALIA
}

\begin{abstract}
In the course of a series of experiments concerned primarily with contrast effects in the itadgment of lifted weights, a set of results has accumulated that appears to speak decisively against a power law for lifted weight (Stevens \& Galanter, 1957). In each case the method of direct magnitude estimation was employed. The purpose of this paper is to present the results as a collection and to comment briefly on their significance.
\end{abstract}

\section{METHOD AND RESULTS}

The data to be reported were collected in experiments designed to investigate separate problems. The results reported below represent the portions of the four experiments that are relevant to the argument presented in this paper. The description of experimental procedure has been limited to the portion of each experiment that is relevant to the present report.

\section{Experiment I}

The Ss were 12 boys, approximately 17 years old, attending a metropolitan school in Perth, Western Australia.

The stimulus objects were 17 opaque plastic cylinders, $53 \mathrm{~mm}$ in diam and $73 \mathrm{~mm}$ high, containing lead and paraffin wax to the required weights, which ranged from 100 to $900 \mathrm{~g}$ in steps of $50 \mathrm{~g}$.

The $S$ was seated at a table opposite $E$ and placed his hand through a cloth screen hiding the weights. $\mathrm{He}$ was read the following instructions:

"You will be presented with a series of weights. The weights will be presented one at a time. Each time I put a weight in your hand, I would like you to lift it once and then put it down. You should lift the weight with a motion of the hand and wrist only, leaving your forearm resting on the table. After you put the weight down, I would like you to tell me your judgment of the heaviness of that weight. In making your judgment, I do not want you to use ounces or pounds or grams or any other standard measure of weight. Instead, I would like you to use numbers. The very first weight that you judge you will call 100 , and your judgment of all subsequent weights should be proportional to the first weight. Thus, if the second weight feels

Fig. 1. Mean magnitude estimates for each group averaged over Trials 6 to 10 . twice as heavy as the first, you will call it 200. If another weight feels half as heavy as the very first weight you lifted, you should call it 50 , and so on."

The standard stimulus, presented once only at the beginning of the experiment was the $500 \mathrm{~g}$ weight. The $S$ then judged all 17 weights for 10 trials. Each trial consisted of the presentation of 17 weights in random order. The order was independently randomized for each trial but was used for all Ss in the group.

\section{Experiment II}

The Ss were seven male students 20 to 24 years old, selected haphazardly from the graduate students in the Department of Psychology at the University of Western Australia. The procedures were the same as in Experiment I except that the standard stimulus was a weight of $480 \mathrm{~g}$, and the stimulus series consisted of nine stimulus objects of the following weights (in g): $220,320,420,480,550,620,700$, and 780 .

\section{Experiment III}

The $S$ s were five male students from the same population as in Experiment II. The procedures were the same as in Experiment 1 except that the standard stimulus was a weight of $300 \mathrm{~g}$ and the stimulus series consisted of nine stimulus objects of the following weights (in g): $250,300,350,450,500,550,650,700$, 750.

\section{Experiment IV}

Method and procedures were the same as in Experiment HII except that the standard stimukus was a weight of $700 \mathrm{~g}$.

For each experiment, the magnitude estirnates made on Trials 6 to 10 were averaged across Ss separately for each weight. The results are shown in Fig. 1. The characteristic double inflection of the judgmental functions shown in Fig. 1 represents the typical result of individual Ss and is not an artifact due to averaging processes.

\section{DISCUSSION}

The doubte inflection shown in each experiment is inconsistent with a power function of any exponent, since a power function is uniformly concave or convexThe same general function form appears despite variation in $S s$, in the range of comparison weights, in the number of stimuli, in the weight of the standard, and in the position of the standard with respect to the comparison range. It also appears despite variatien between experiments and between $S s$ within experiments in the range of numerical estimates used (cf. Luce \& Mo, 1965). The last fact argues against the double inflection's being caused by a ceiling on the numbers $S s$ are prepared to use.

Ross and Di Lollo (1968) have shown that psychophysical functions for different standards are not related by simple multiplicative transformations. The form

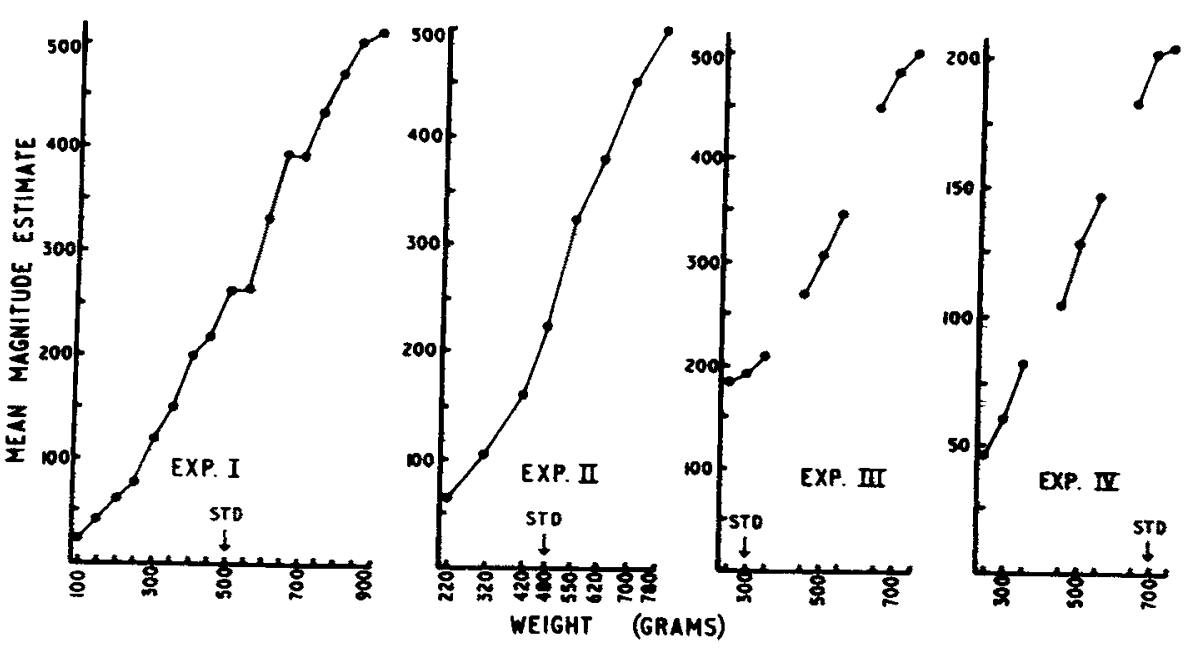


of the psychophysical function varies with the standard. They argued that there is no single psychophysical function, the power law or any other, and proposed instead a model for the judgments made in magnitude estimation, which could account for the strong interaction of series judged with the standard, and for the consistent violation of the power law demonstrated in this paper.

\section{REFERENCES}

LUCE, R. D., \& MO, S. S. Magnitude estimation of heaviness and loudness by individual subjects: A test of a probabilistic response theory. British Journal of Mathematical \& Statistical Psychelogy, 1965, 18, 159-174.

ROSS, J., \& DI LOLLO, V. A vector model for psychophysical judgment. Journal of Experimental Psychology Monograph Supplement, 1968, 77, No. 3, Part 2.

STEVENS, S. S., \& GALANTER, E. Ratio scales and category scales for a dozen perceptual continua. Journal of Experimental Psychology. 1957, 54. 377-411.

NOTES

1. This research was supported by the Australian Research Grants committee under Grant No. ARG 17-226 to both authors.

2. Address: Department of Psychology, The University of Western Australia, Nedlands, W. A. 6009

(Accepted for publication February 9, 1970.) 